\title{
Random shaped ZnO supported on a porous substrate as supercapacitor
}

\author{
Rupashree S. Ray ${ }^{\mathrm{a}}$, Biplab Sarma ${ }^{\mathrm{a}}$, and Mano Misra ${ }^{\mathrm{a}}$, b, 1 \\ ${ }^{a}$ Metallurgical Engineering Department, University of Utah, Salt Lake City, UT 84112, USA \\ ${ }^{\mathrm{b}}$ Chemical Engineering Department, University of Utah, Salt Lake City, UT 84112, USA
}

Keywords: Electrochemical Capacitor, Zinc Oxide, Nanocomposites, Supercapacitor, Electrodeposition, Titania Nanotube

\begin{abstract}
Potentiostatic depositions of zinc oxide $(\mathrm{ZnO})$ on titania $\left(\mathrm{TiO}_{2}\right)$ nanotube substrate have been observed to demonstrate remarkable enhancement in the supercapacitance behavior as reported in this study. Systematic evaluation of the morphology and crystal structure of the electrodeposited $\mathrm{ZnO}$ phase was carried out using scanning electron microscopy (SEM) and Xray diffraction (XRD) techniques, respectively. The cyclic voltammetry and galvanostatic charge-discharge experiments indicated that the electrode can attain a maximum specific capacitance of $304 \mathrm{~F} \mathrm{~g}^{-1}$ that was partly attributed to the electro-active $\mathrm{ZnO}$ phase and partly to the highly permeable, porous, and unidirectional nanotubular $\mathrm{TiO}_{2}$ substrate.
\end{abstract}

\section{Introduction}

Nanotubular morphology of $\mathrm{TiO}_{2}$ (T-NT) is of particular interest for various applications, especially because of its certain peculiar properties: high surface area, good chemical stability and non-toxicity $[1,2]$. As supercapacitor electrode, the specific capacitance of T-NT is quite low $\left(\sim 0.1 \mathrm{mF} \mathrm{cm}^{-2}\right)[3]$, however its presence as a supporting base/substrate in combination with

${ }^{1}$ Corresponding author: mano.misra@utah.edu 
various electro-active metal oxides has proven to produce substantial enhancement in the supercapacitance behavior [4-6]. Metal oxides such as $\mathrm{NiO}, \mathrm{Bi}_{2} \mathrm{O}_{3}$, and $\mathrm{Co}_{2} \mathrm{O}_{3}$ were used previously to fabricate composite electrodes with $\mathrm{T}-\mathrm{NT}$ in order to promote the overall capacitance properties [4-6]. Recently, $\mathrm{ZnO}$ based electrodes were studied for their capacitance properties $[7,8]$. It has been argued that high electrochemical capacitance behavior (typically of the order of $100-200 \mathrm{~F} \mathrm{~g}^{-1}$ ) observed in this class of oxide material is due to its good electrochemical attributes as well as favorable electronic properties $[7,8]$.

This study has been conducted to evaluate the supercapacitance behavior of T-NT/ZnO composite electrode. The composite electrodes were synthesized using a simple, easy to implement electrodeposition technique. The fabricated T-NT/ZnO electrode indeed showed promising supercapacitance properties due to the favorable combinations of an electro-active oxide phase and porous supporting nanotubular substrate.

\section{Experimental studies}

\subsection{T-NT Substrate Fabrication}

Titantium samples $(0.1 \mathrm{~mm}$ thickness and $10 \mathrm{~mm}$ x $15 \mathrm{~mm}$ ) were roughly polished (with 600 grit $\mathrm{SiC}$ emery paper) and ultrasonically cleaned in a solution of acetone and isopropyl alcohol (1:1). Subsequently, the coupons were anodized potentiostatically in an electrolyte $(0.5$ wt $\%$ ammonium fluoride and $10 \% \mathrm{H}_{2} \mathrm{O}$ ) at $40 \mathrm{~V}$ for 1 hour. Subsequently, the anodized titanium samples were annealed in air at $500^{\circ} \mathrm{C}$ for 2 hours.

\subsection{Electrochemical Deposition of $\mathrm{ZnO}$}

Potentiostatic deposition of $\mathrm{ZnO}$ on T-NT surface was carried out in an aqueous solution of 10 $\mathrm{mM}$ zinc chloride and $0.5 \mathrm{M} \mathrm{KCl}$ at $60^{\circ} \mathrm{C}$. A 3-electrode based electrochemical workstation 
(Gamry Reference 600) with annealed T-NT coupon as working electrode, platinum coil as counter electrode and a saturated $\mathrm{Ag} / \mathrm{AgCl}$ electrode as reference constituted the electrochemical deposition setup. Depositions were carried out at a constant potential $\left(-1.25 \mathrm{~V}_{\text {ref } \mathrm{Ag} / \mathrm{AgCl}}\right)$ for various durations of time (5-20 min).

\subsection{Characterization}

Examination of the surface and cross sectional morphology of T-NT and T-NT/ZnO samples was performed using a field emission scanning electron microscope (FE-SEM, Hitachi S-4800). The XRD analysis of the samples was carried out using SIEMENS D5000 diffractometer with copper $\mathrm{K}-\alpha$ radiation.

\subsection{Electrochemical Measurements}

The electrochemical properties of the T-NT/ZnO electrodes were evaluated by conducting cyclic voltammetry $(\mathrm{CV})$ and galvanostatic charge-discharge experiments in $0.1 \mathrm{M} \mathrm{Na} \mathrm{SO}_{4}$ using a potentiostat (Gamry Reference 600), connected to a 3-electrode setup consisting of the T$\mathrm{NT} / \mathrm{ZnO}$ sample as the working electrode, platinum coil as the counter electrode, and saturated $\mathrm{Ag} / \mathrm{AgCl}$ electrode as a reference electrode.

\section{Results and Discussion}

Anodization of $\mathrm{Ti}$ produced self-organized and vertically aligned nanotube array (T-NT) as shown in Fig. 1a. The nanotubes were found to have an average diameter of $\sim 90 \mathrm{~nm}$, length of $\sim$ $1.5 \mu \mathrm{m}$ (inset Fig. 1a) and wall thicknesses in the range of $15-20 \mathrm{~nm}$.

Potentiostatic deposition of $\mathrm{ZnO}$ on T-NT substrate resulted in the formation of irregular shaped morphology of the oxide phase after various deposition times. Fig. 1(b-e) shows the $\mathrm{ZnO}$ deposits obtained after the deposition times of $t=5,10,15$, and 20 minutes. Some important 
observations can be made from these micrographs. In general, the deposits appeared to be irregular, although occasional hexagonal nano-sized crystals as well as rod-shaped oxide phases were visible from the micrographs which were also observed in a previous study [9]. As the deposition time was increased, the amount of oxide deposits was also increased. One interesting observation was that the size of the $\mathrm{ZnO}$ crystals decreased after the deposition time was increased from 10 to 15 minutes. For example, after deposition for 10 minutes, the $\mathrm{ZnO}$ crystals were approximately 0.5-1 $\mu \mathrm{m}$ (Fig. 1c), however, after 15 minutes, the crystals became 200-500 nm (Fig. 1d). One possible reason for the decreased $\mathrm{ZnO}$ crystal size could be due to the change in the concentration of the $\mathrm{Zn}^{2+}$ in the deposition electrolyte after prolonged deposition time [9]. Also evident from the micrograph in Fig. 1d, the deposits became more uniformly distributed on the surface of the T-NT after 15 minutes of deposition. Such distribution of the oxide phase is important for electrochemical charge storage application as it provides well-balanced optima of sufficient electroactive material for the redox reactions as well as a good accessibility for the electrolyte to permeate through the porous T-NT substrate for efficient intercalation. Further increase in the deposition time to 20 minutes, the $\mathrm{ZnO}$ crystal density was increased although size of the oxide phase remained the same as that obtained after 15 minutes (Fig. 1e). In Fig. 1e, agglomeration of the $\mathrm{ZnO}$ crystals was also visible after 20 minutes of deposition.

The XRD analysis conducted on the T-NT/ZnO electrode prepared for $t=15 \mathrm{~min}$ indicated the formation of crystalline $\mathrm{ZnO}$ phase. The XRD profile presented in Fig, 2 indicated the presence of diffraction peaks from (110) and (103) planes of the $\mathrm{ZnO}$ phase agreeing well with the literature reported data $[7,8]$. Please note that some of the peaks from the anatase phase of the TNT as well as Ti-substrate can also be observed in the XRD profile. 
The cyclic voltammetry $(\mathrm{CV})$ profiles, recoded at $200 \mathrm{mV} \mathrm{s}^{-1}$ for the electrodes prepared for various deposition durations are shown in Fig. 3a. The profiles, irrespective of the deposition time, appeared to be the mixture of the pseudo as well as EDL type capacitance behavior. The pseudo nature of the electrodes is due to the redox reactions that might have occurred at around $0.4 \mathrm{~V}$ (vs $\mathrm{Ag} / \mathrm{AgCl}$ ref. electrode) as evident in the $\mathrm{CV}$ profiles. Moreover, the current responses in the CV profiles exhibit mirror-image behavior about the zero-current line with rapid current reversals at each potential limit $[1,2]$. It is also interesting to note that the electrodes prepared for $t=15$ min showed relatively higher capacitance compared to all other electrodes - a relatively higher enclosed CV area for this electrode can be observed in comparison to the other electrodes. The reason for the increased capacitance for this electrode can be argued based on the $\mathrm{ZnO}$ morphology/distribution observed for this electrode (Fig. 1c). The uniform distribution of the $\mathrm{ZnO}$ crystallites (no agglomeration) along the entire T-NT substrate resulted significantly higher intercalation with the electrolyte during the $\mathrm{CV}$ process along with the optimum access of the electrolyte for efficient permeation into the porous T-NT substrate that lies beneath the oxide phase. The deposition processes for shorter durations $(t=5,10 \mathrm{~min})$ resulted in lesser weight fraction of $\mathrm{ZnO}$, while with increased deposition time $(t=20 \mathrm{~min})$ agglomeration of the oxide phase was observed leading to the incomplete intercalation of the oxide phase. From the CV curves, the specific capacitance $(C)$ of the electrodes was calculated using the following equation $[3,5,10-12]$

$C=Q / \Delta V m$

Where $Q=$ half of the total charge from the integrated $\mathrm{CV}$ area, $\Delta V=$ voltage window, $m=$ mass of $\mathrm{ZnO}$ deposit. Using Eqn. 1, the specific capacitance were calculated to be about 92, 103, 154 
and $139 \mathrm{~F} \mathrm{~g}^{-1}$ for the electrodes prepared for $t=5-20$ minutes, respectively and plotted in the inset of Fig 3(a).

Further, CV experiments were performed at different scan rates for the electrode prepared for $t=$ 15 min and presented in Fig. 3(b). It is apparent from the figure that the shape of the CV curves did not vary with the change in the scan rates demonstrating good stability of the electrode material. The specific capacitance of the electrode were $302,198,154 \mathrm{~F} \mathrm{~g}^{-1}$ at the scan rates of 20, 100 and $200 \mathrm{mV} \mathrm{s}^{-1}$. The specific capacitance decreased by about $50 \%$ upon increase in the scan rate from 20 to $200 \mathrm{mV} \mathrm{s}^{-1}$ - such decrease in capacitance can be attributed to the incomplete intercalation between the $\mathrm{ZnO}$ and the electrolyte at higher scan rates as described previously in more details [3,5].

Fig. 3(c) shows the representative charge-discharge profile for the electrodes prepared for $t=15$ min of deposition obtained after conducting galvanostatic charge-discharge cycle test at a current density of $3 \mathrm{~mA} \mathrm{~cm}^{-2}$. The experiments were conducted for 1000 continuous cycles and the specific capacitance obtained were plotted and presented in Fig. 3(d). The tests demonstrated that the capacitance retention for the electrode was excellent with only $10 \%$ fading of the capacitance value after 1000 continuous charge-discharge cycles.

\section{Conclusion}

The synthesis of composite electrodes comprising of zinc oxide $(\mathrm{ZnO})$ and titania nanotubes $(\mathrm{T}$ NT) using a simple electrodeposition process has been carried out. SEM and XRD analysis on the composite electrodes suggested evolution of various morphologies (random, hexagonal rounded and rod shaped) and crystalline phases of the $\mathrm{ZnO}$ deposit. The cyclic voltammetry and 
galvanostatic charge discharge tests conducted using the electrodes suggested that a high capacitance value $\left(\sim 300 \mathrm{~F} \mathrm{~g}^{-1}\right)$ can be achieved in the electrode by suitably optimizing the electrodeposition parameters.

\section{Acknowledgement}

The authors acknowledge U.S. Department of Energy (DE-FC-36-06GO86066) for the financial support supported to carry out the work presented here.

\section{References}

1. Smith Y, Ray RS, Carlson K, Sarma B, Misra M, Self-Ordered Titanium Dioxide Nanotube Arrays: Anodic Synthesis and Their Photo/Electro-Catalytic Applications, Materials, 2013;6 : 2892-2957

2. Wang G, Zhang L, Zhang J., A review of electrode materials for electrochemical supercapacitors, Chem. Soc. Rev., 2012; 41: 797-828

3. Ray RS, Sarma B, Jurovirtski AL, Misra M, Fabrication and Characterization of Titania Nanotube/Cobalt Sulfide Supercapacitor Electrode in Various Electrolytes, Chemical Engineering Journal, 2015; 260:671-683

4. Xie, Y.; Zhou, L.; Huang, C.; Huang, H.; Lu, J. Fabrication of nickel oxide-embedded titania nanotube array for redox capacitance application, Electrochim. Acta, 2008; 53,3643-3649.

5. Sarma B, Smith Y, Jurovirtski AL, Mohanty SK, Misra M, Redox-Induced Enhancement in Interfacial Capacitance of the Titania Nanotube/Bismuth Oxide Composite Electrode, Appl Mater Inter. 2013; 5:1688-97

6. Zhou, H, Zhang, Y, Electrochemically Self-Doped TiO2 Nanotube Arrays for Supercapacitors, J. Phys. Chem. C, 2014; 118: 5626-5636

7. Zhang. Y, Sun. X, Pan. L, Li. H, Sun Z, Sun. C, Tay. B., Carbon nanotube-zinc oxide electrode and gel polymer electrolyte for electrochemical supercapacitors, Journal of Alloys and Compounds 2009; 480: L17-L19

8. Selvakumar, M. Bhat D, Aggarwal A, Iyer S, Sravani G, Nano ZnO-activated carbon composite electrodes for supercapacitors, Physica B 2010; 405: 2286-2289 
9. Nisanc1 F, Öznülüer T, Demir U, Photoelectrochemical properties of nanostructured ZnO prepared bycontrolled electrochemical underpotential deposition, Electrochimica Acta, 2013; 108:281- 287

10. Sarma B, Ray RS, Mohanty SK,, Misra M, Synergistic Enhancement in the Capacitance of Nickel and Cobalt Based Mixed Oxide Supercapacitor Prepared by Electrodeposition, Appl. Surf. Sci. 2014;300:29-36

11. Sarma B, Jurovirtski A, Smith Y, Ray RS, Misra M, "Influence of Annealing Temperature on the Morphology and the Supercapacitance Behavior of Iron Oxide Nanotube (Fe-NT)", Journal of Power Sources, 2014; 272:766-775

12. Lokhande C.D., Dubal D.P., Joo Oh-Shim, Metal oxide thin film based supercapacitors, Current Applied Physics. 2011; 11: 255-170 
Figure 1: (a) The top view of the T-NT after anodization (inset shows the cross-sectional view), morphologies of the $\mathrm{ZnO}$ deposit after deposition time ( $t$ ) of (b) $5 \mathrm{~min}$, (c) $10 \mathrm{~min}$, (d) $15 \mathrm{~min}$ and (e) $20 \mathrm{~min}$.

Figure 2: XRD profile of the T-NT/ZnO electrode prepared for $t=15 \mathrm{~min}$

Figure 3: (a) CV profiles of the T-NT/ZnO electrodes prepared for $\mathrm{t}=5-20 \mathrm{~min}$ (inset shows the variations in the specific capacitance $(C)$ with $t$ ) (b) $\mathrm{CV}$ curves recorded at various scan rates for the T-NT/ZnO electrode prepared for $\mathrm{t}=15 \mathrm{~min}$ (c) Representative galvanostatic chargedischarge profiles obtained at a current density of $3 \mathrm{~mA} \mathrm{~cm}$ on the T-NT/ZnO electrode prepared for $\mathrm{t}=15 \mathrm{~min}$. (d) Variations in the $C$ of the $\mathrm{T}-\mathrm{NT} / \mathrm{ZnO}$ electrode prepared for $\mathrm{t}=15$ min. as the function of cycle number. 


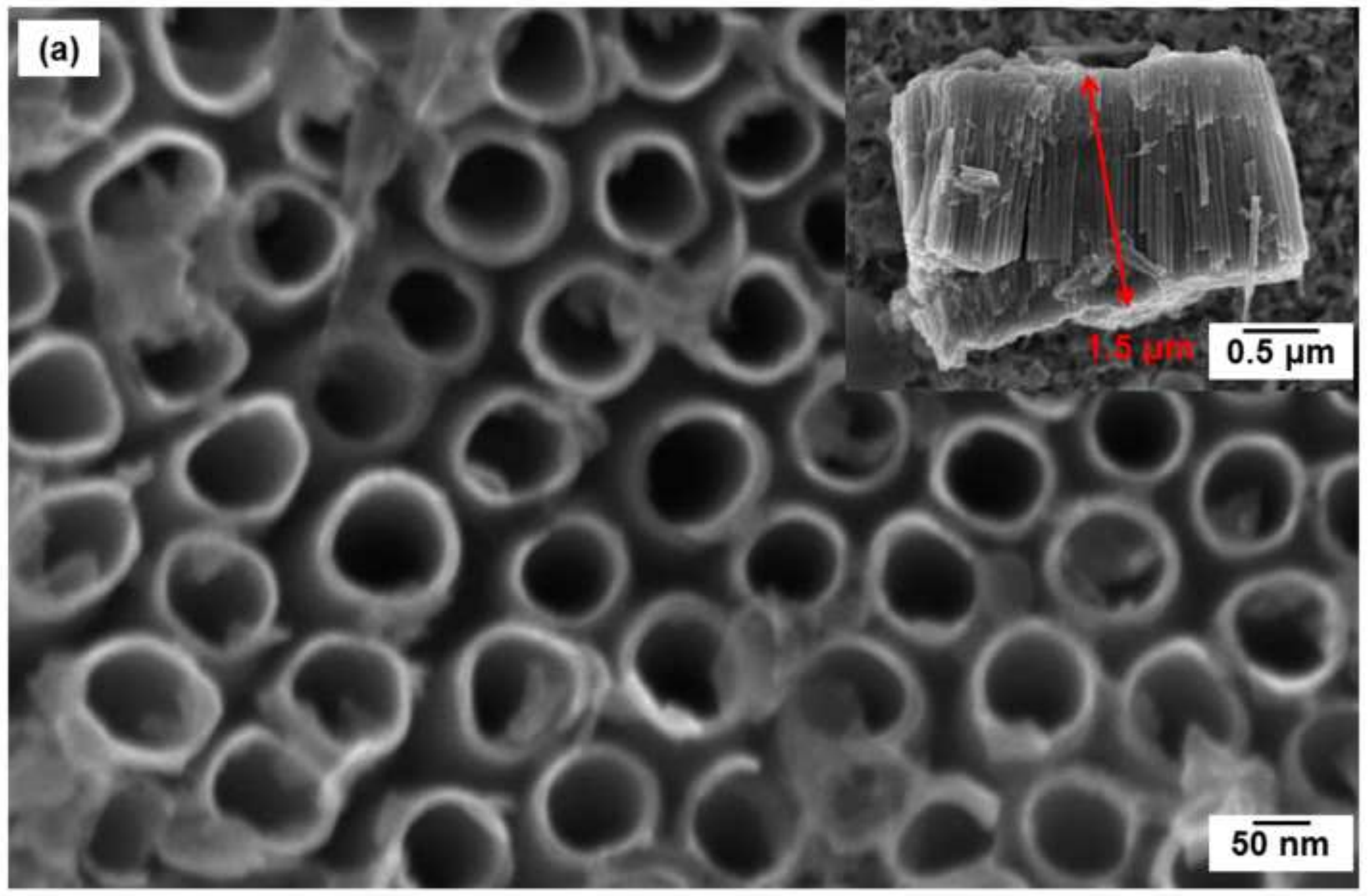




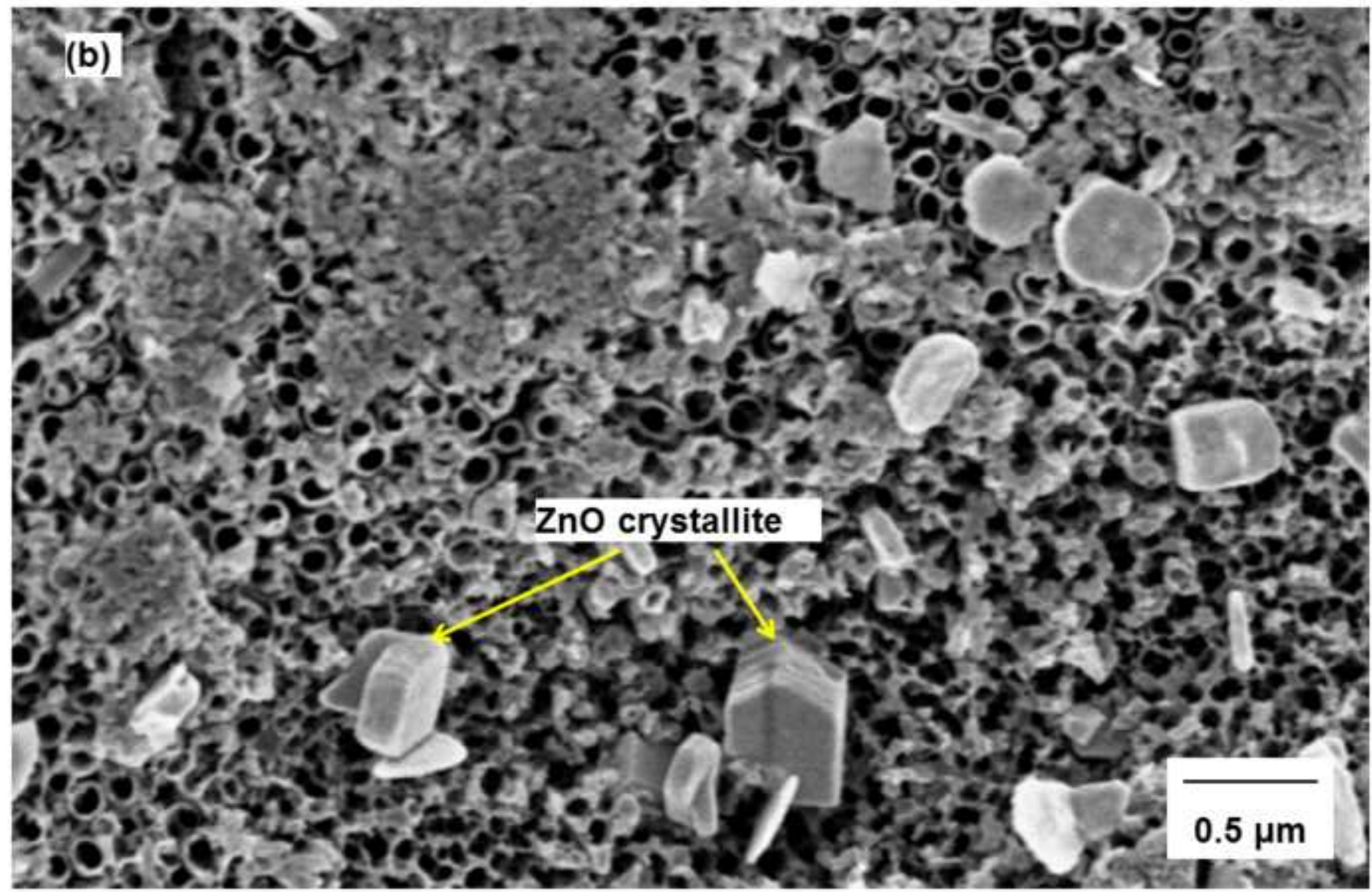




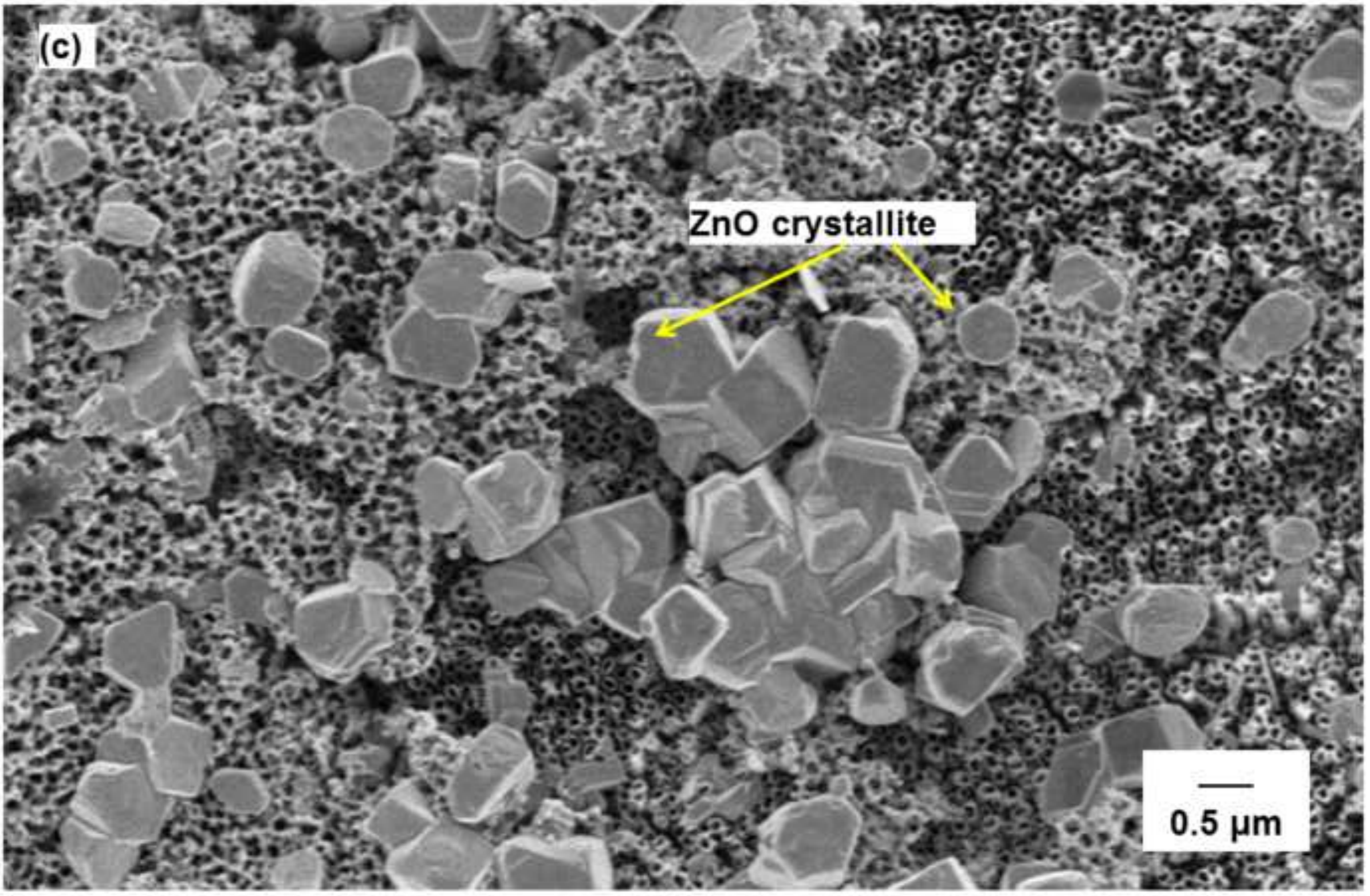




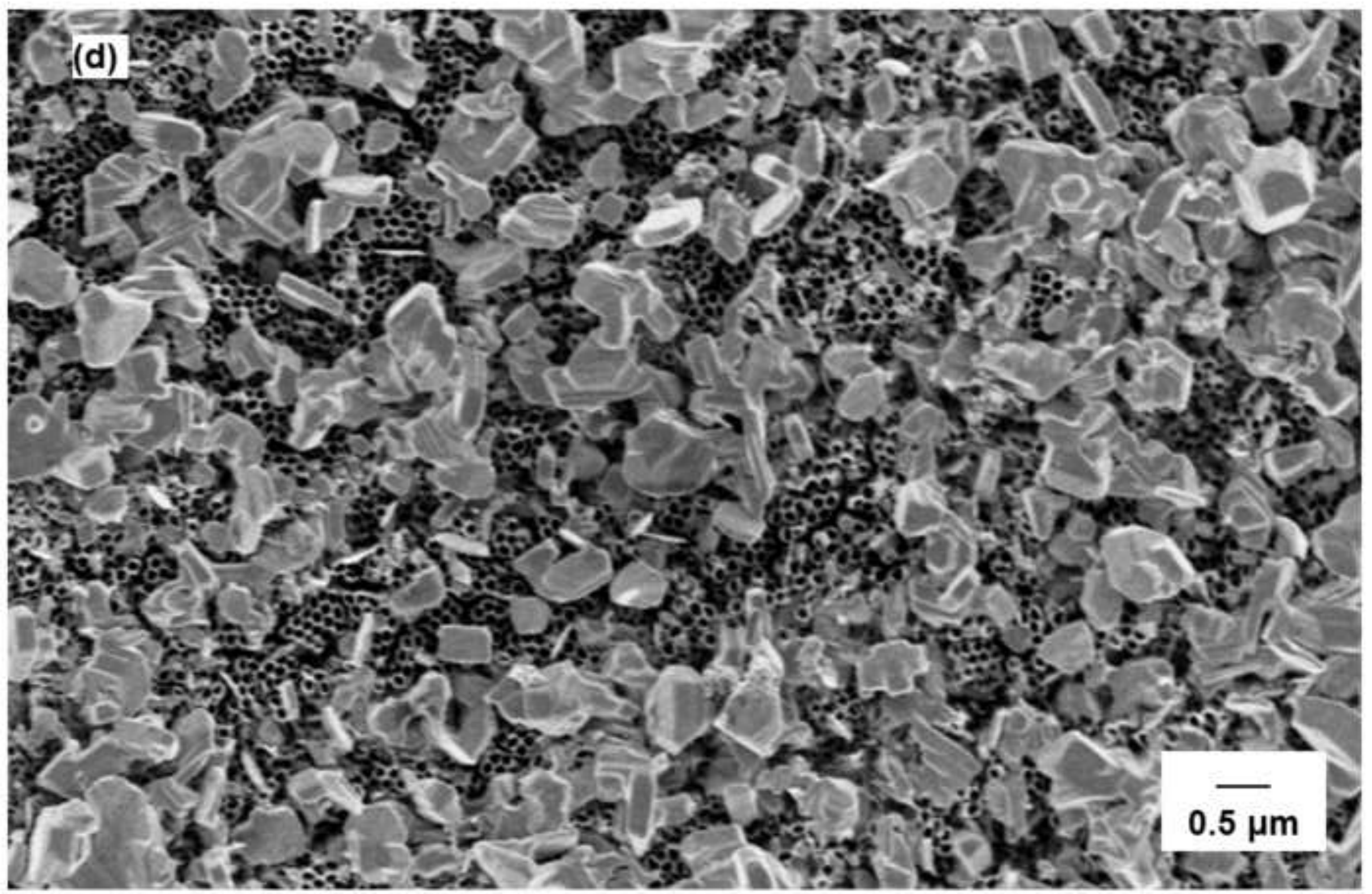




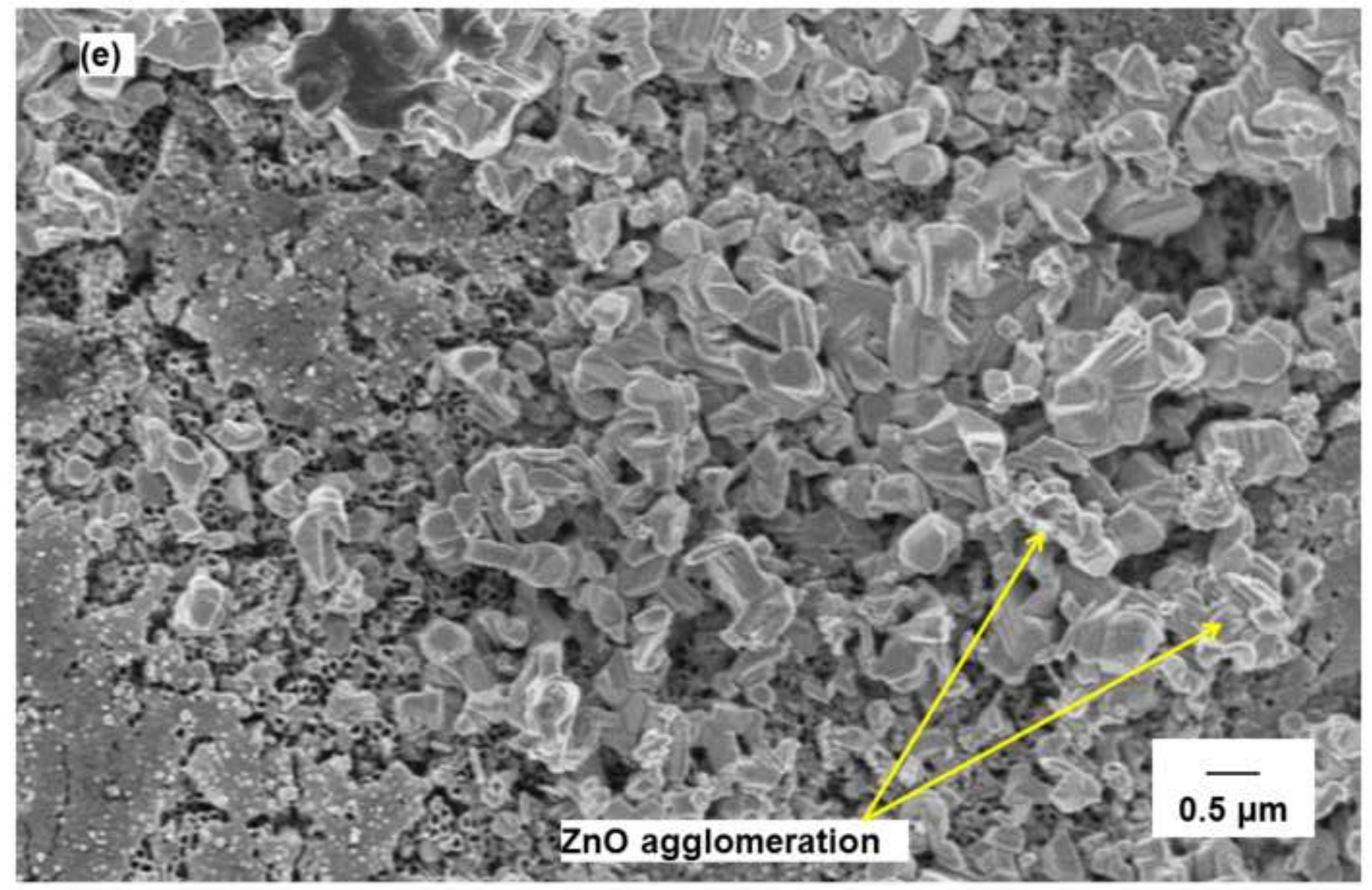




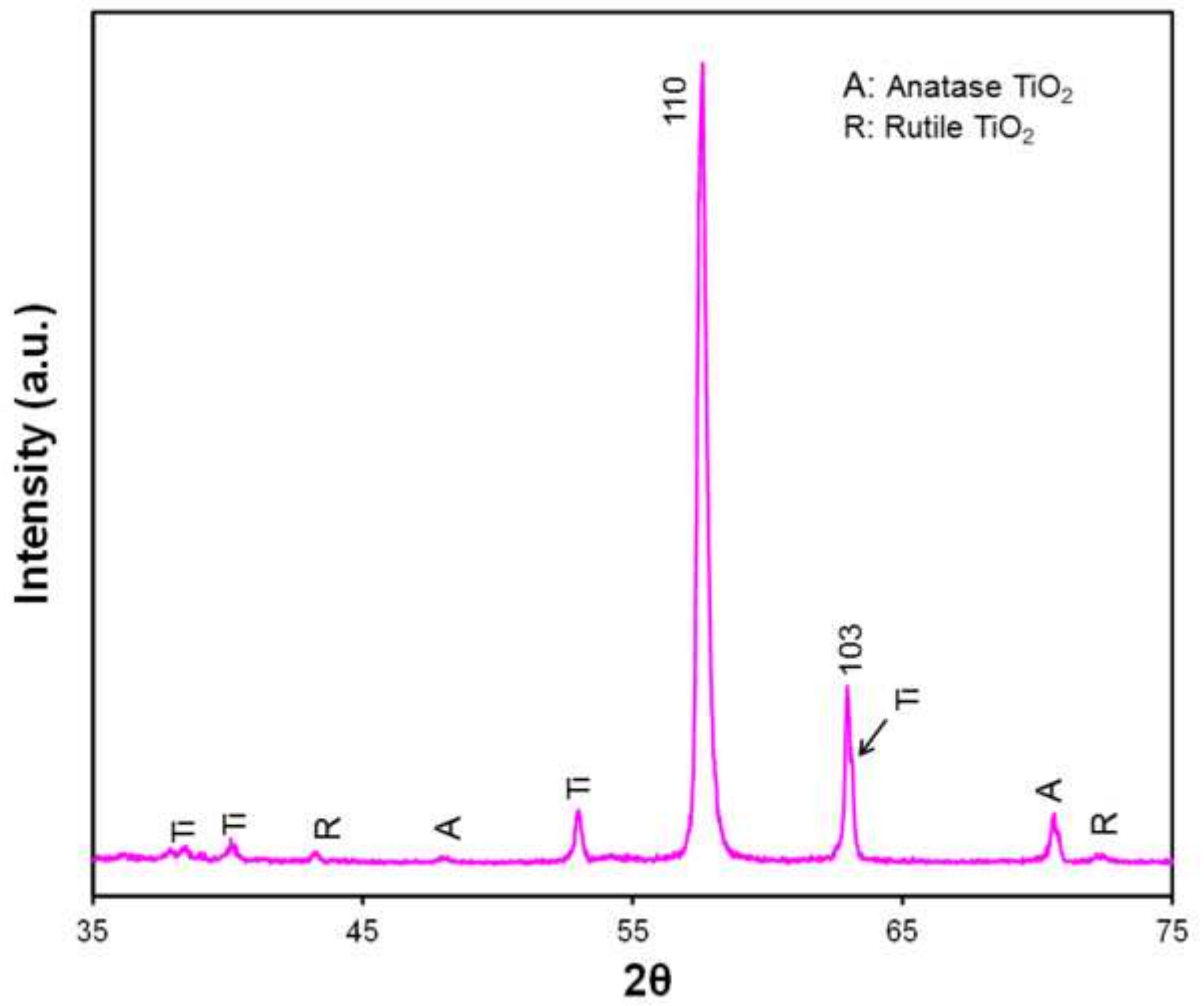




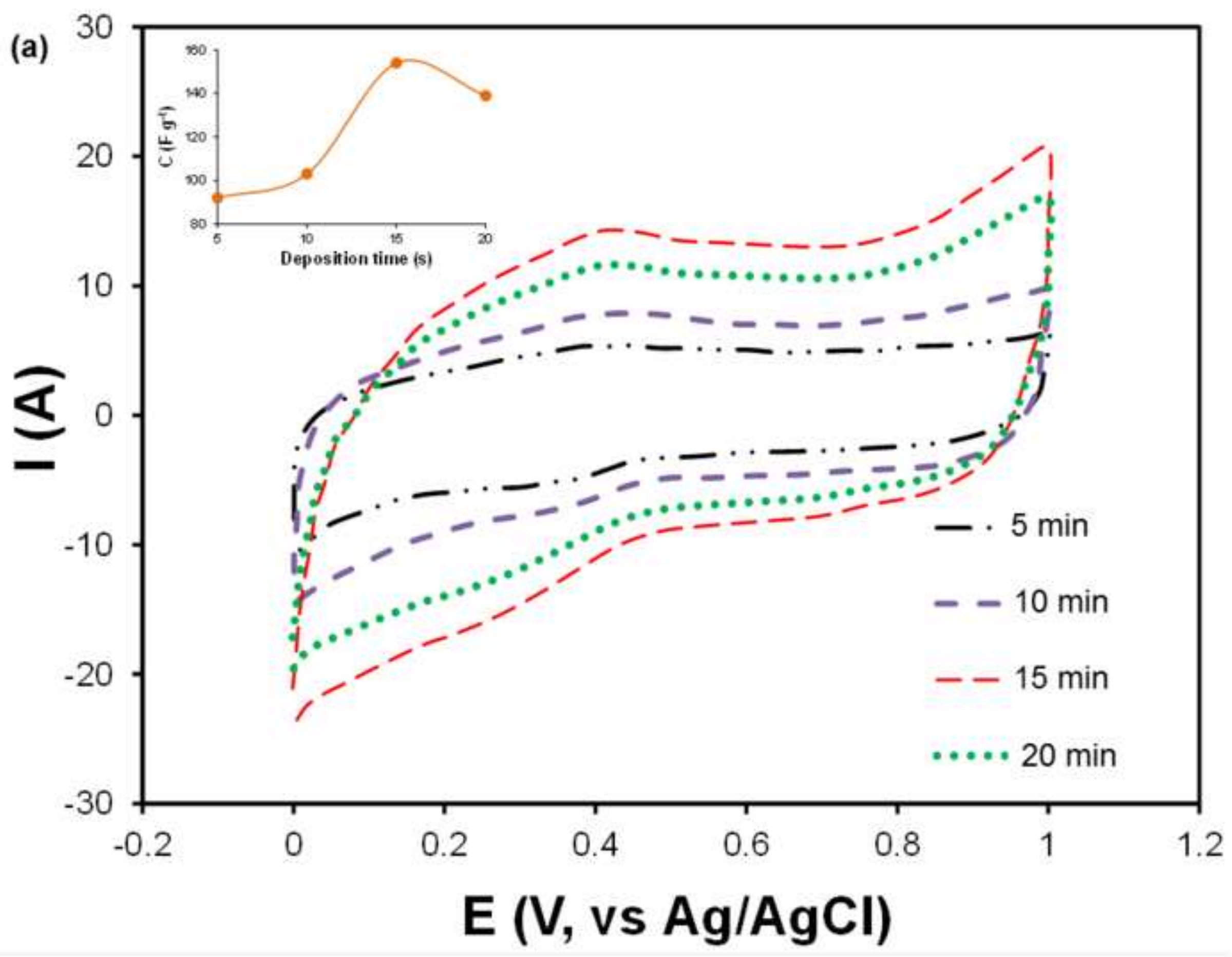




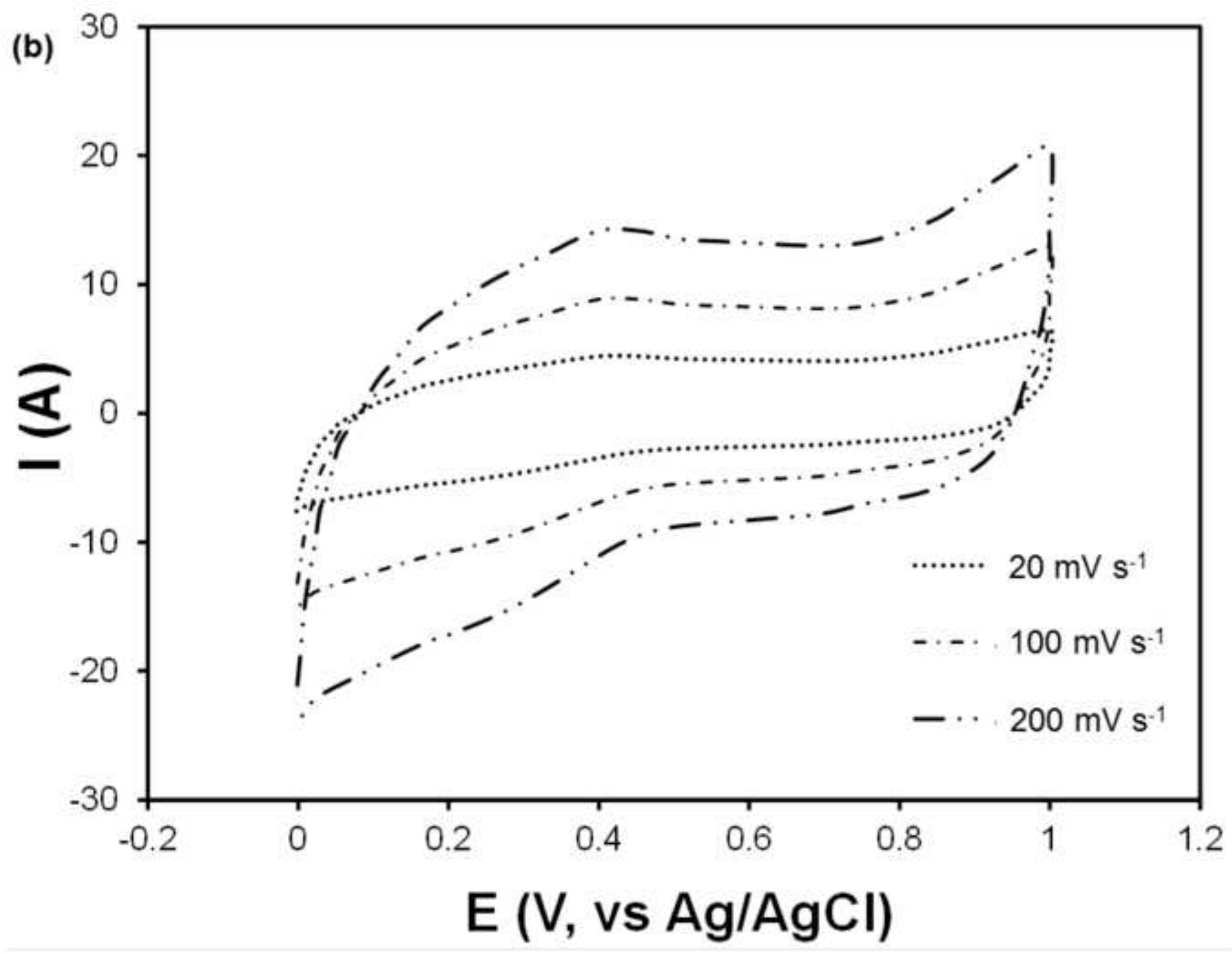




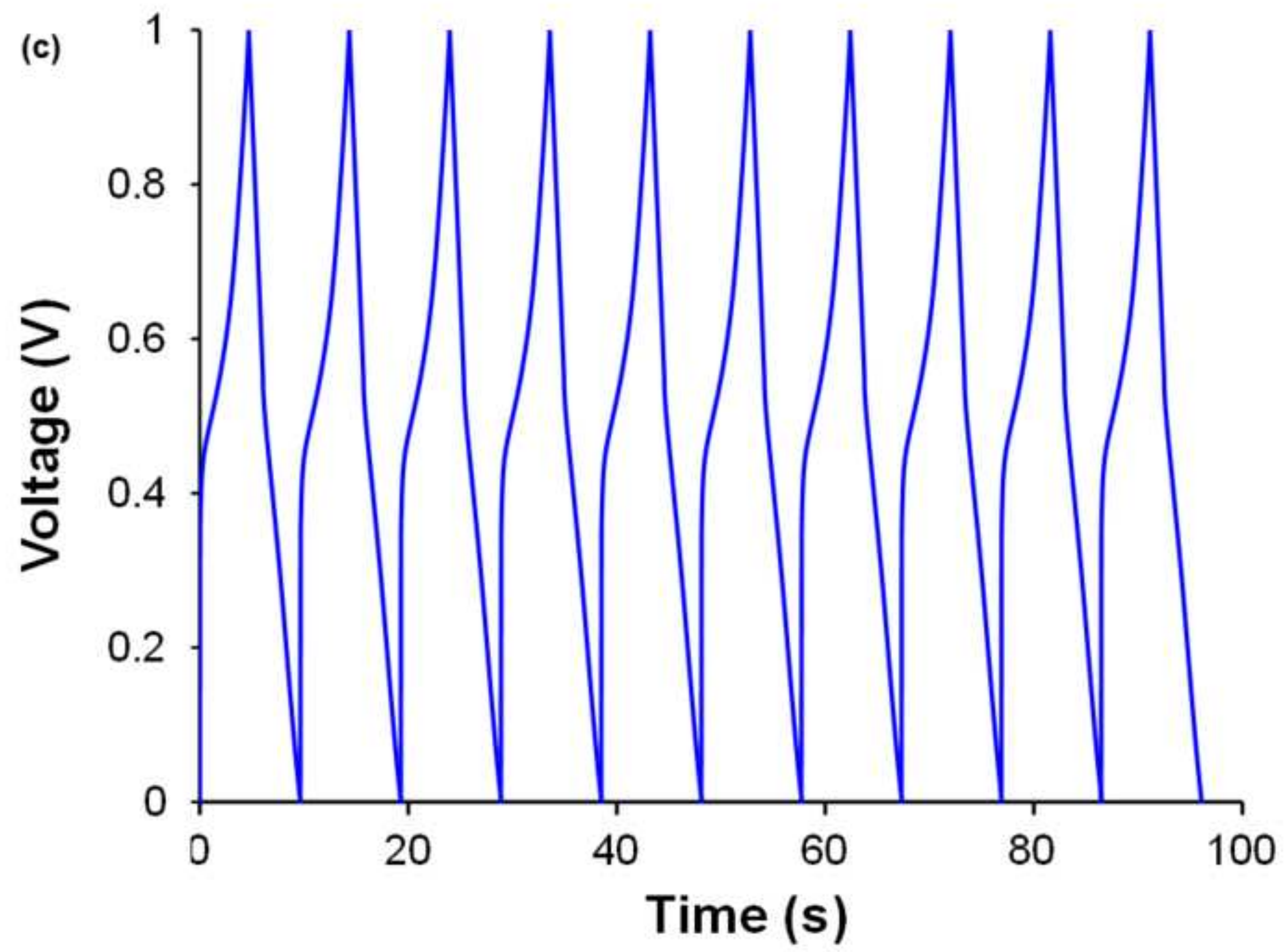




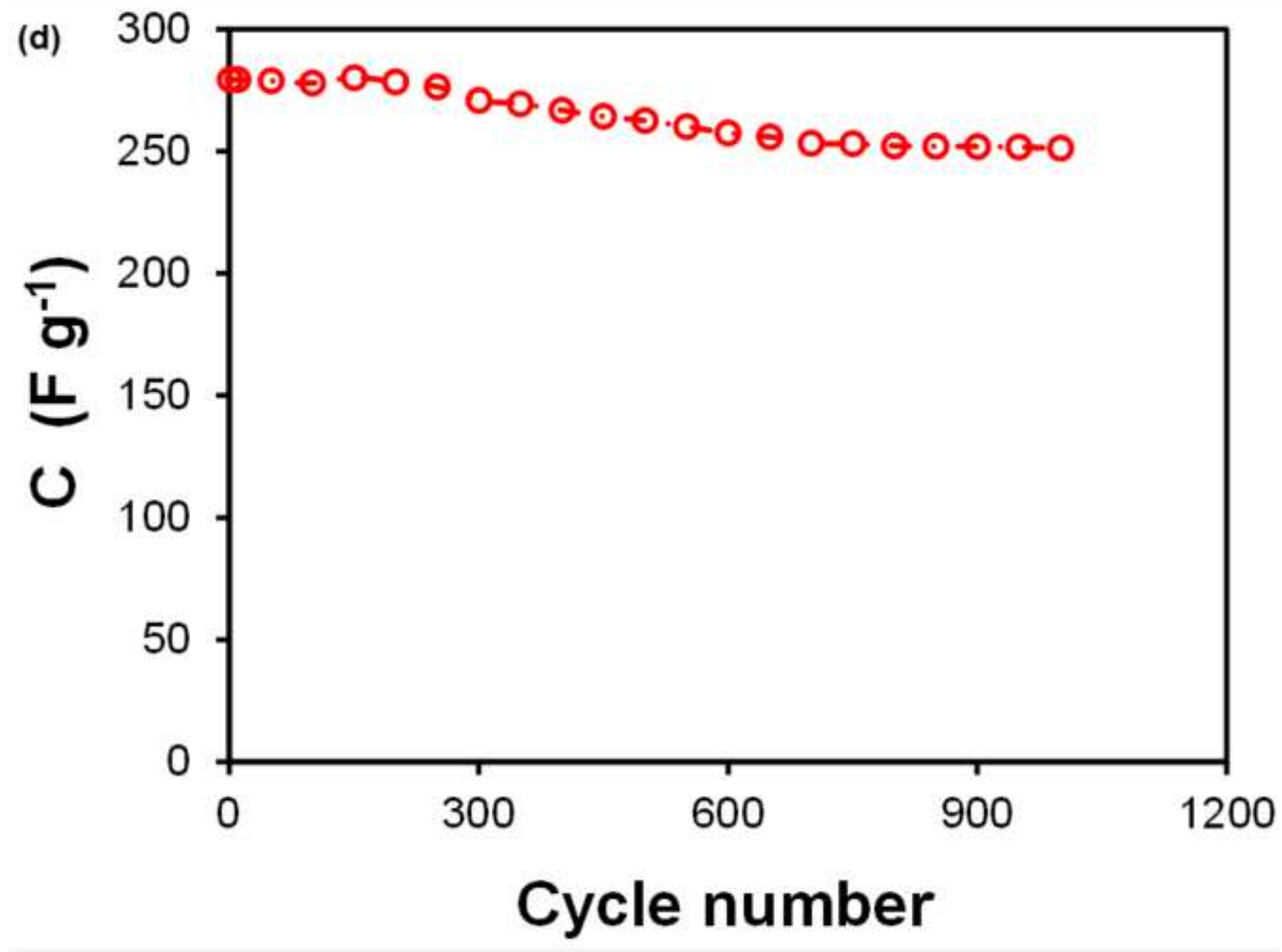

